\title{
A Study on the Cooling Load of Small Cabins for One Person
}

\author{
Dong-Hyun Cho \\ The University of Daejin, 1007, Hogukro, Pocheonsi, Gyeinggodo, 11159, South \\ Korea \\ chodh@daejin.ac.kr
}

\begin{abstract}
This study was conducted to lay cold water panels inside the ocher walls of a small cabin for one person and install cold water tubes inside the cold-water panels for radiant cooling with the absorption of thermal energy by the cold water for the first time at home and abroad. One-person households are increasing, and the current number of one-person households is about 5.61 million, accounting for $28.6 \%$ of all households. One-person households are still gradually increasing. However, study reports on small cabins for one person are rare at home and abroad. Therefore, this study was conducted to examine the sizes of beds for small houses for one person, which can be utilized as beds at normal times and can be used to take cold pack at home by those who like cold pack in hot summer. The findings of this study, which include the results of simulations of changes in the flow rate of the cold water circulating in the cold water panels of small cabins for one person and the distribution of the temperatures of the air inside the small cabins for one person in relation to changes in the outdoor temperatures in summer, indicated that the air temperature inside the small cabins for one person was linearly reduced by the radiative heat transfer and that well-being low-temperature distributions beneficial to health were shown.
\end{abstract}

Keywords: Small cabins, Cold-water, Cooling load, Thermal energy, Cold water panel

\section{Introduction}

One-person households are increasing, and the current number of one-person households is 6.61 million (National Statistics Office, total census data), accounting for $28.6 \%$ of all households [1]. One-person households are still gradually increasing. However, study reports on small cabins for one person are rare at home and abroad. In addition, since the demand for buildings not larger than 2 Pyeong such as pensions, ocher rooms, and small accommodations is gradually increasing and such buildings rely on fans or natural ventilation for cooling even in hot summer, study reports on suitable cooling technologies for such buildings are desperately required, but the current study reports are insufficient [2]. In addition, cooling systems for summer are mainly supplied to buildings that use them for rooms not smaller than 8 Pyeong, and there are many study reports on cooling technology for the forced convective heat transfer by air circulation method [3]. As the demand for houses of one-person households is gradually increasing, studies on technologies for cooling systems suitable for small cabins for one person are urgently required, but the current study result reports are insufficient [4]. In addition, study reports on cooling technologies for elderly persons' small cabins for one person, which are beneficial to both sleeping and health, are desperately required but such study reports are still

Article history:

Received (February 3, 2021), Review Result (March 5, 2021), Accepted (April 10, 2021) 
somewhat insufficient [5]. Therefore, it is considered that if a bed for small houses for one person that can be also used as an ocher cold pack room is studied and supplied based on the results of this study, elderly persons' health will be improved substantially thanks to comfortable sleep and ocher room radiant heat cold pack. In addition, since there are no suitable cooling system accessories (circulation pump, heater, etc.) required for residential spaces not larger than 1 Pyeong, accessories suitable for buildings larger than 8 Pyeong are used in buildings not larger than 1 Pyeong leading to great electric power energy losses and large installation charges. Therefore, this study was conducted to implement a small cabin for one person which can be also used as an ocher cold pack room with an area of $2 \mathrm{~m}^{2}$ with cold water panels laid in its walls, in which cold water is circulated to absorb radiant heat for well-being room cooling beneficial to health. In addition, ocher beds and ocher walls, which were verified as being beneficial to health in the results of many previous studies and references, were constructed so that residential life on bed and ocher cold park room were implemented simultaneously [6]. A well-being cooling technology beneficial to health was developed by implementing ocher radiant heat cooling by constructing the bed and walls to have ocher coldwater panels. Since there is a risk of facial nerve palsy when the bed floor is cold, room cooling in summer was implemented with radiant cooling through the cold water circulating only in the ocher cold-water panels laid in the walls to develop well-being cooling technology beneficial to health. In addition, this study was conducted to develop a technology for ocher cold pack rooms for summer implemented through the reduction and control of the temperature of the cold water circulating in the wall cold water panels so that cold pack can be taken in the bed space depending on the taste of the residents.

Furthermore, this study ensured that in spring and autumn, the ceiling of the small cabin for one person, which is also used as an ocher cold pack room, can be placed at the height of the ceiling of the room, the walls of the bed are placed in close contact with the walls of the room, and the front door of the cabin can be widely opened or easily detached so that the cabin can provide the same feeling and sense as general beds thereby being used as a bed. In addition, this study ensured that the relevant cabin can be used to take radiant heat cold pack at any time even in spring or autumn depending on the taste of the resident by closing the door and operating the radiant heat cold pack room. In addition, whereas the existing cooling of oneperson houses heated the entire room $\left(10\right.$ to $\left.13 \mathrm{~m}^{2}\right)$, in this study, a technology that can cool only the bed space $\left(2 \mathrm{~m}^{2}\right)$ was developed to significantly reduce the cooling energy consumption rate.

\section{Experimental apparatus and method}

[Figure 1] shows the experimental apparatus for small cabins for one person, in which cooling is implemented as the cold water circulating in the tubes of the cold-water panels laid in the ocher walls of the small cabins for one person absorb the thermal energy held in the hot air inside the space of the small cabin for one person. Fig. 2 shows a 3D plan of a small cabin for one person in which cooling is implemented as the cold water circulating in the tubes of the cold-water panels laid in the ocher walls of the small cabin for one person absorb the thermal energy held in the hot air inside the space of the small cabin for one person. As shown in Fig. 1 and Fig. 2, in this study, cold water panels were laid in the ocher walls of the small cabin for one person, and cold-water tubes were installed inside the cold-water panels to carry out radiant cooling with the absorption of thermal energy by the cold water to fabricate and study the relevant experimental apparatus for the first time at home and abroad. The size of the small cabin for one person is $2000 \mathrm{~mm}$ wide, $1100 \mathrm{~mm}$ long, and $1800 \mathrm{~mm}$ high. The width and length of the small cabin for one person were made to be the same as those of a single bed so 
that the small cabin for one person can be used as a bed at normal times and can be used to take cold pack at home by those who like cold pack in summer. In addition, the cooling area of the experimental apparatus for small cabins for one person is $2 \mathrm{~m} 2$, and cold-water panels were laid inside the walls to configure the experimental apparatus so that cold water is circulated inside the cold-water panels thereby implanting the natural convective radiative heat transfer to carry out an experimental study and 3D simulations to implement well-being cooling beneficial to health. The experimental study and 3D simulations were carried out so that residential life on bed and ocher cold pack room can be simultaneously implemented by constructing an ocher bed and ocher walls. Ocher cold-water panels were constructed in the bed and the walls to implement natural convective radiative heat transfer cooling thereby implementing a wellbeing cooling technology beneficial to health. Since there is a risk of facial nerve palsy when the bed floor is cold, room cooling in summer was implemented with radiant cooling through the cold water circulating only in the ocher cold-water panels laid in the walls to develop wellbeing cooling technology beneficial to health. In addition, the study was conducted to develop a technology for ocher cold pack rooms in summer implemented through the reduction and control of the temperature of the cold water circulating in the wall cold water panels so that cold pack can be taken in the bed space depending on the taste of the residents [7].

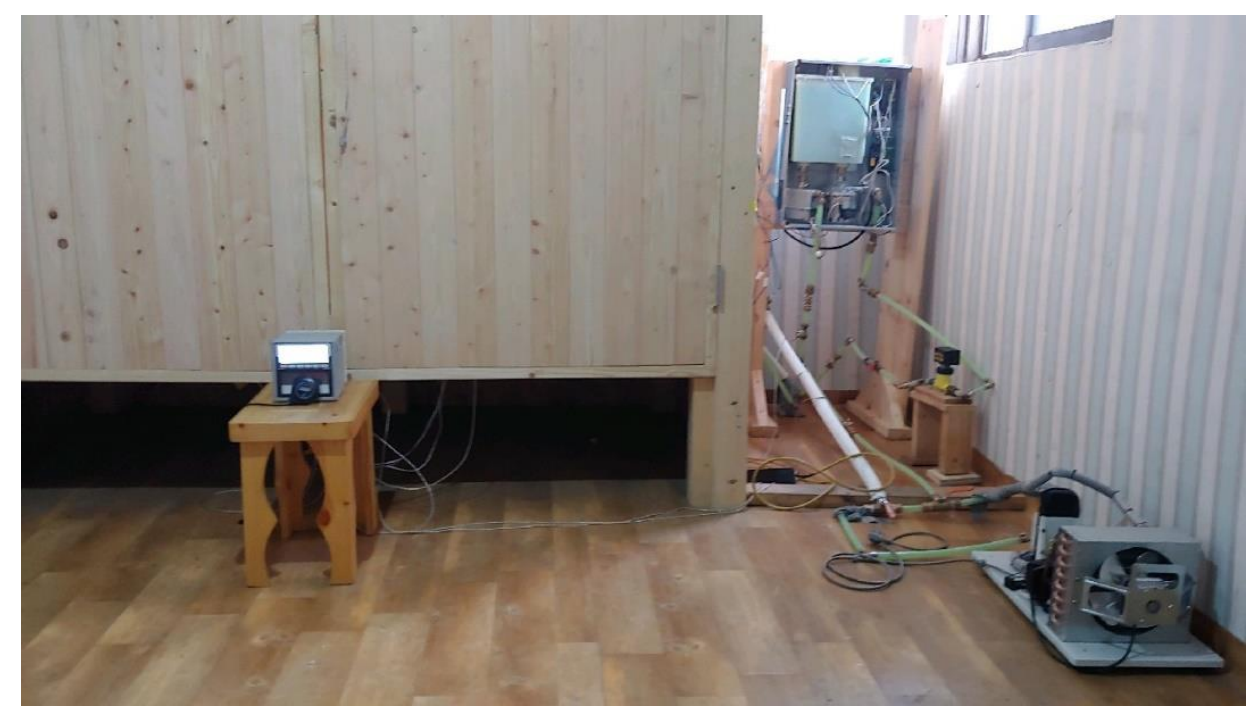

Figure 1. Experimental apparatus for natural convective radiative heat transfer cooling load for small cabins for one person

In addition, this study ensured that in spring and autumn, the ceiling of the small cabin for one-person household, which is also used as an ocher cold pack room, can be placed at the height of the ceiling of the room, the walls of the bed are placed in close contact with the walls of the room, and the front door of the cabin can be widely opened or easily detached so that the cabin can provide the same feeling and sense as general beds thereby being used as a bed. In addition, this study ensured that the relevant cabin can be used to take radiant heat cold pack at any time even in spring or autumn depending on the taste of the resident by closing the door and operating the radiant heat cold pack room. In addition, whereas the existing cooling of oneperson houses heated the entire room (10 to $13 \mathrm{~m} 2)$, in this study, a technology that can only cool the bed space $(2 \mathrm{~m} 2)$ was developed to significantly reduce the cooling energy consumption rate. This study fabricated an experimental apparatus for ocher cold pack room 
that went beyond the jjimjilbang culture to enable people to take cold pack at the houses they reside and investigated the temperature distribution characteristics of the cold pack room. As a result of this study as such, comfortable cooling and well-being cooling beneficial to health were implemented because unlike forced convection cooling in which air is forcibly circulated by the air conditioner, natural convective radiative heat transfer cooling implements cooling without moving or circulating air. An experimental apparatus was constructed to implement cooling by circulating cold water through cold water tubes laid in the walls of the small cabin for one person by configuring a chiller and a cold-water pump to supply cold water to the coldwater panel. Existing small cooling devices are for cooling of houses or offices not smaller than 8 Pyeong and achieve cooling by forced convection methods. However, study reports are insufficient for cooling devices for small cabins for one person not larger than 2 Pyeong investigated in this study. Therefore, this study investigated a cooling system that can be used in small buildings such as pensions not larger than 2 Pyeong.

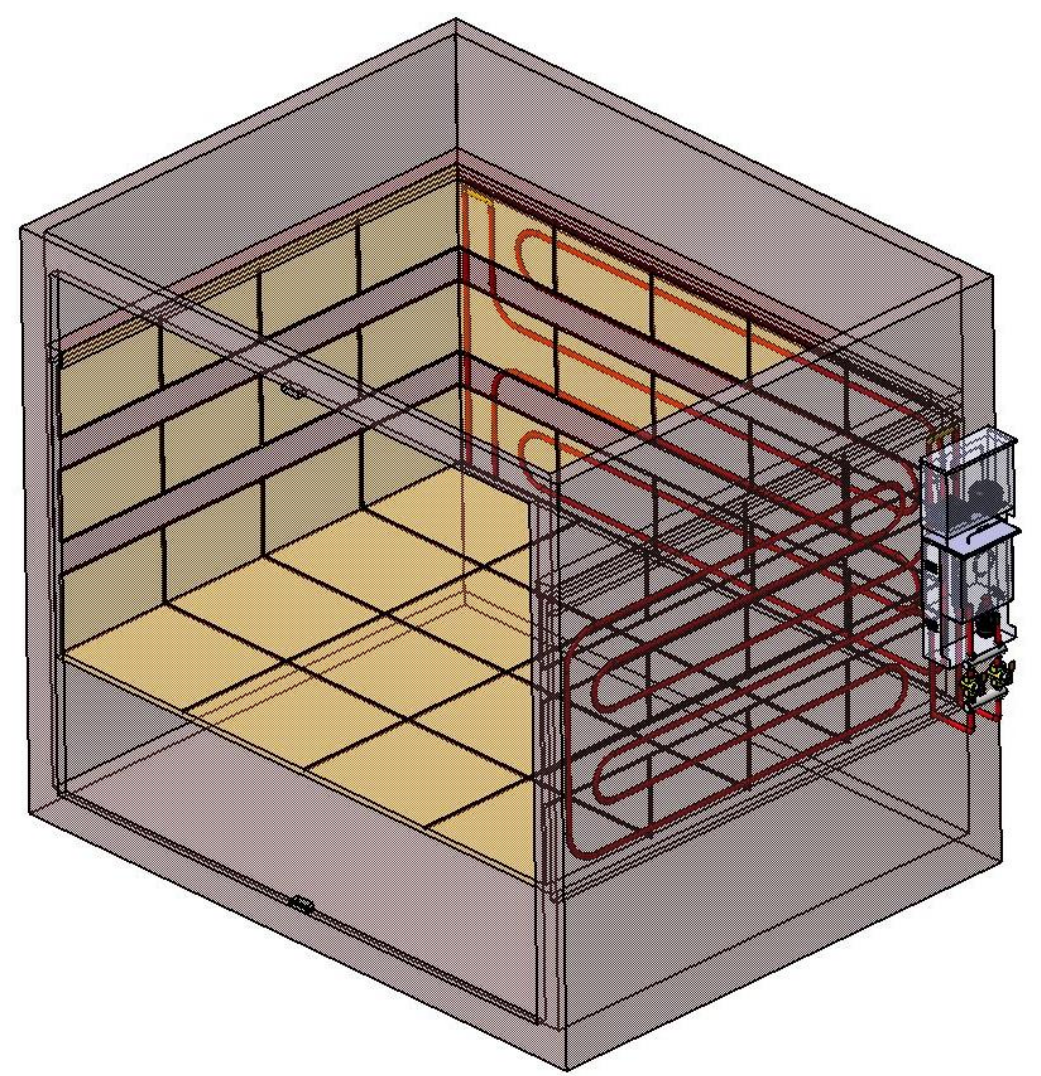

Figure 2.3D plan of the experimental apparatus for natural convective radiative heat transfer cooling load for small cabins for one person

As shown in [Figure 3], a chiller for supplying cold water was installed on the cold-water panels of small cabins for one person to carry out an experimental study. The chiller for cold water supply was studied to have a noise level of $40 \mathrm{~dB}$ in the study so that there was no sleep disturbance caused by noises when sleeping in the small cabin for one person at night. By studying indoor low-noise chiller technology as such, this study was conducted to prevent energy losses exceeding 3\% when compared to the case where the existing technology was installed outdoors considering outdoor cooling losses and pipe losses. 


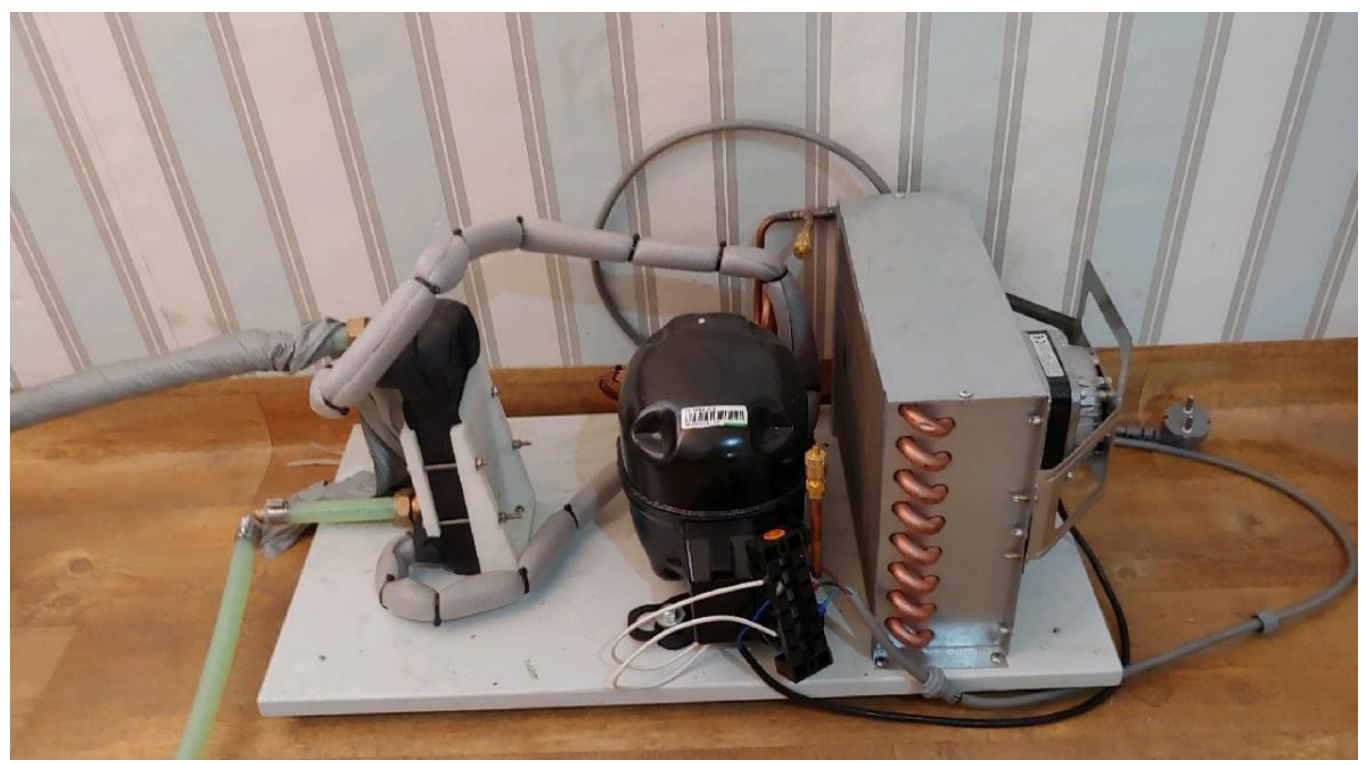

Figure 3. Chiller for cold water supply to the cold-water panels of the small cabins for one person

\section{Result}

\subsection{D simulation of cooling load in relation to changes in the air temperature inside the small cabin for one person}

[Figure 4] and [Figure 5] shows the analysis shape and analysis mesh of the cooling load simulation for changes in the air temperature inside the small cabin for one person. The size of the small cabin for one person one-person is 2,000 mm wide, 1,050 $\mathrm{mm}$ long, and 2,200 $\mathrm{mm}$ high. As shown in Fig. 4, the simulation was carried out when the temperature of the cold water flowing into the inlet of the cold-water panel laid inside the walls and floor inside the small cabins for one person was $0.3{ }^{\circ} \mathrm{C}$. In addition, the simulation was carried out under the conditions of a flow rate of cold water of $3 \mathrm{~L} / \mathrm{min}$ and an outdoor temperature of $32^{\circ} \mathrm{C}$. ANSYS FLUENT R19 was used as analysis software. Fig. 5 shows the results of simulations of the surface temperatures of the ocher walls and ocher floor inside the small cabins for one person and the air temperature distribution and air flow distribution in the space inside the small cabin for one person. The size of the small cabins for one person is 2,000 mm wide, 1,050 $\mathrm{mm}$ long, and 2,200 mm high. As shown in Fig. 5, the simulation was carried out when the temperature of the cold water flowing into the inlet of the cold-water panel laid inside the ocher walls inside the small cabin for one person was $0.3{ }^{\circ} \mathrm{C}$. In addition, the simulation was carried out under conditions of a flow rate of cold water of $2.8 \mathrm{~L} / \mathrm{min}$ and an outdoor temperature of $32{ }^{\circ} \mathrm{C}$. ANSYS FLUENT R19 was used as analysis software. The natural convective heat transfer inside the small cabin for one person was simulated with gravity and incompressible ideal gas air. The results of simulation of the temperature distribution of air inside small cabins for one person in Fig. 5 showed that the average temperature of the air inside the small cabin for one person was $26.17^{\circ} \mathrm{C}$, the air temperature at a height of $300 \mathrm{~mm}$ from the base side of the small cabin for one person was $26.57^{\circ} \mathrm{C}$, and , the air temperature at a height of $1,000 \mathrm{~mm}$ from the base side of the small cabin for one person was The air temperature at a height of 1,000 $\mathrm{mm}$ from the bottom of the one-person household was $26.17^{\circ} \mathrm{C}$. The results of simulation of the air temperature distribution indicated that the temperature distribution of the cold air due to the 
natural convective radiative heat transfer inside the small cabin for one person was uniform, which is considered as a well-being temperature distribution beneficial to health. In this study, the temperature distribution of the cold air measured in the experimental study and the temperature distribution of the cold air shown in the simulation results were in good agreement.
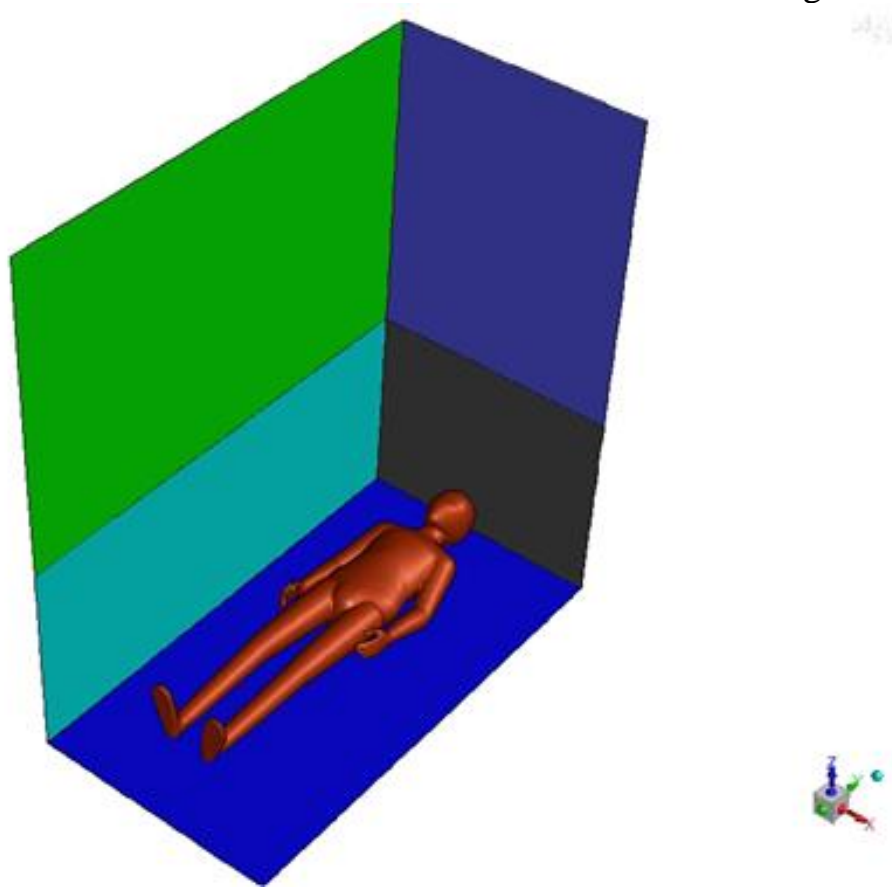

Figure 4. Analysis shape of simulation of cooling load in relation to changes in the temperature of air inside the small cabin for one person
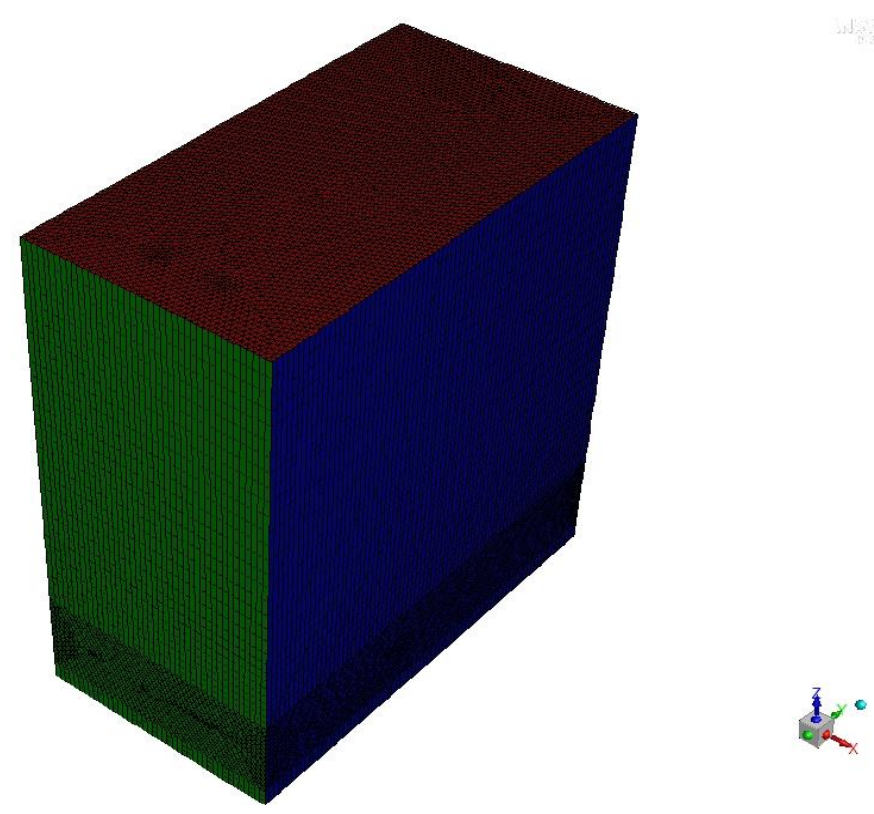

Figure 5. Analysis mesh for simulation of cooling load in relation to changes in the temperature of air inside the small cabin for one person 

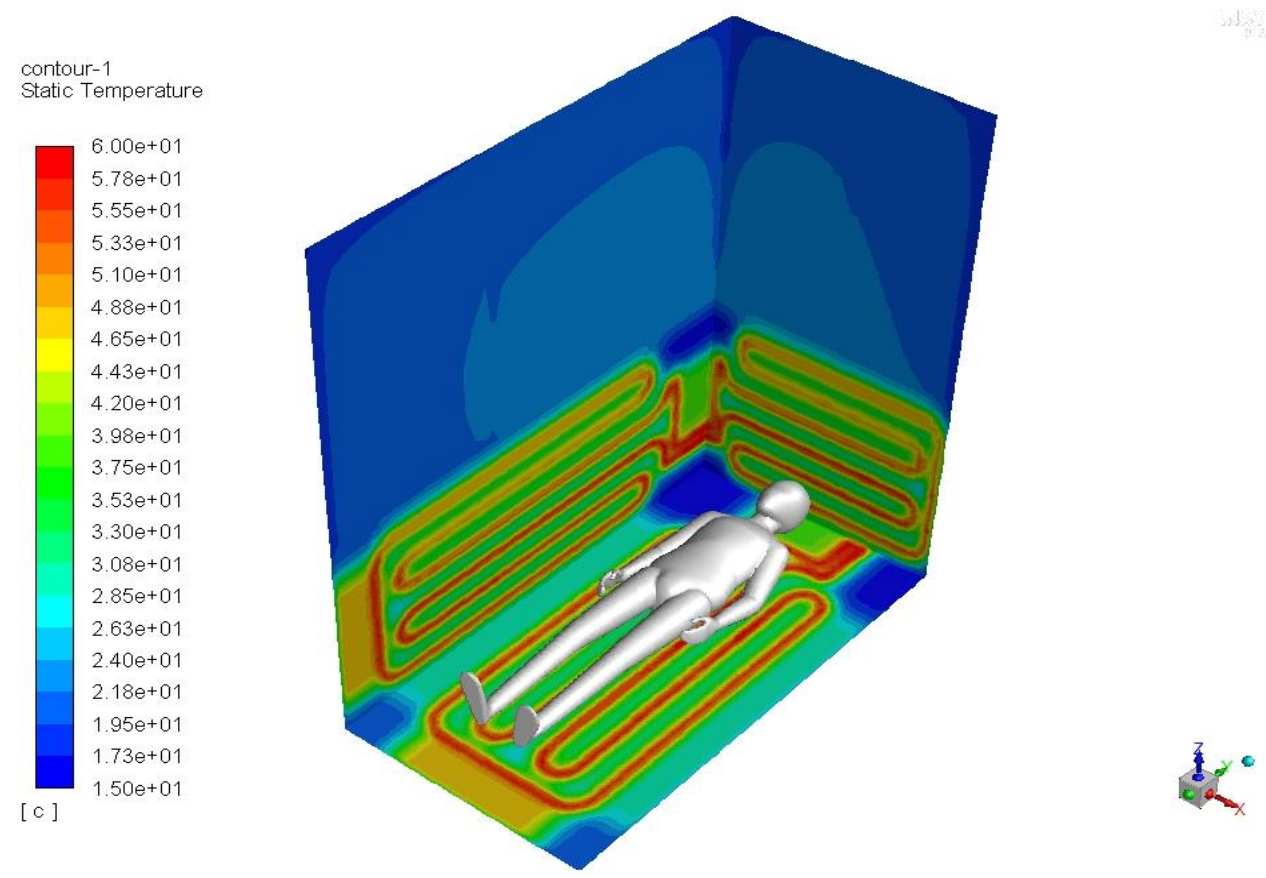

Figure 6. Distribution of temperatures of the walls inside the small cabin for one person

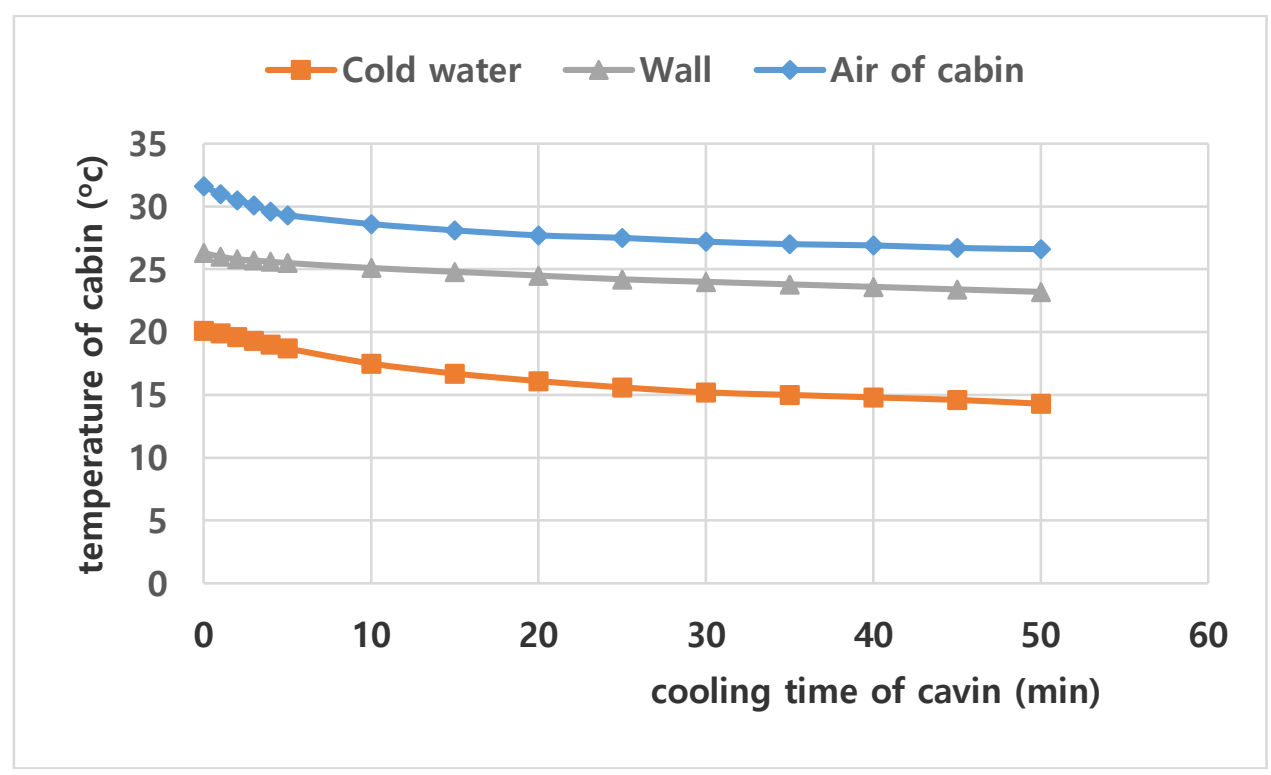

Figure 7. The rate of changes in the temperature of the cold air inside the small cabin for one person in relation to changes in the flow rate of the cold water circulating in the cold-water tube inside the walls of the mall cabin for one person

\subsection{Characteristics of the cooling load of small cabins for one person due to heat absorption of cold water}

[Figure 7] shows changes in the temperature of the cold air inside the small cabin for one person following changes in the flow rate of the cold water circulating inside the tubes in the cold-water panel laid on the walls. The cold-water flow rates were experimented under three 
conditions: $1.5 \mathrm{~L} / \mathrm{min}, 3.0 \mathrm{~L} / \mathrm{min}$, and $6 \mathrm{~L} / \mathrm{min}$. As shown in Fig. 7, the temperature of the cold air inside the small cabin for one person decreased in proportion to the increase in the flow rate of cold water, and in proportion to the cooling time. Therefore, the temperature of the cold water produced by the chiller was normally increased as the cold water absorbed the thermal energy held by the air existing in the small cabin for one person. In addition, it is considered that the cooling load of the small cabin for one person increases as the cold-water flow rate increases. Furthermore, based on the results of the experiments conducted with the small cabin for one person, the balance of heat energy for cooling was achieved well. Therefore, the reliability of the experimental results in this study was verified.

\section{Conclusion}

In this study, 3D simulations and experimental studies were carried out on the cooling load due to the heat absorption by water circulating inside the ocher walls of the small cabin for one person, and the following results were derived.

In the cooling of the small cabin for one person, the values of the experimental natural convective heat transfer coefficient and the theoretical natural convective heat transfer coefficient of cold air for cooling were relatively well matched throughout the experiment. Therefore, the reliability of the experimental results for the cooling load of small cabins for one person in this study was verified.

As the mass flow rate of cold water increased, the air temperature in the space in the small cabin for one person decreased proportionally. Therefore, as the cooling water flow increased, the cooling load of the small cabin for one person increased.

In the future, studies on the convective heat transfer coefficient of small cabins are required.

\section{References}

[1] S. Th. Smith, V. I. Handby, and C. Harpham, "A probabilistic analysis of the future potential of evaporative cooling systems in a temperate climate," Energy Buildings, vol.43, no.2-3, pp.507-516, (2011)

[2] A. C. Oliveira, C. F. Afonso, S. B. Rlffat, and P. S. Doherty, "Thermal performance of a novel air conditioning system using a liquid desiccant," Applied Thermal Engineering," vol.20, no.13, pp.1213-11223, (2015)

[3] M. Goldsworthy and S. White, "Optimization of a desiccant cooling system design with indirect evaporative cooler,” International Journal of Refrigeration, vol.34, no.1, pp.148-158, (2011)

[4] Y. Ko, S. Jang, and H. Hong, "A study on condensation occurrence rate of energy recovery ventilator according to latent effectives," Proceedings of SAREK Summer Annual Conference, pp.853-856, (2020)

[5] D. S. Song and Y. H. Choi, "Control strategy of ventilation system with air filtration mode considering indoor and outdoor air quality in residential buildings," Korean Journal of Air-Conditioning and Refrigeration Engineering, vol.31, no.12, pp.568-575, (2019)

[6] M. Bourdeau, "Modeling and forecasting building energy consumption: A review of data-driven techniques," Sustainable Cities and Society, vol,48, pp.101533, (2019)

[7] W. Li and S. Wang, "A multi-agent based distributed approach for optimal control of multi-zone ventilation systems considering indoor air quality and energy use,” Applied Energy, vol,275, pp.115371, (2020) 


\section{Authors}

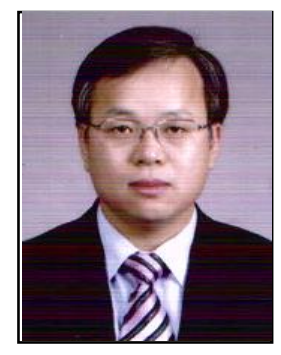

Dong-Hyun Cho

Professor

Daejin University, South Korea 
A Study on the Cooling Load of Small Cabins for One Person

This page is empty by intention. 